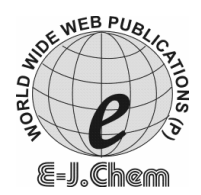

http://www.e-journals.net
ISSN: 0973-4945; CODEN ECJHAO

E-Journal of Chemistry

Vol. 5, No.4, pp. 802-809, October 2008

\title{
Study on the Adsorption Kinetics of Acid Red 3B on Expanded Graphite
}

\author{
XIU-YAN PANG* and FEI GONG \\ College of Chemistry and Environmental Science, \\ Hebei University, Baoding, 071002, People' Republic of China.
}

Received 4 January 2008; Accepted 2 March 2008

\begin{abstract}
Expanded graphite (EG) is a kind of important adsorbent for organic compound such as oil and dyes. We have investigated the adsorption kinetics characteristics of this adsorbent for dye. EG was prepared with 50 mesh crude graphite through chemical oxidation intercalation of potassium permanganate and vitriol, and dye of acid red 3B was used as model sorbate. We have studied the adsorption kinetic models and rate-limiting step of the process. Adsorption rate and activation energy of the adsorption process were calculated. Kinetic studies show that the kinetic data are well described by the pseudo second-order kinetic model. The equilibrium adsorbance increases with the increase of the initial acid red 3B concentration. Initial adsorption rate increases with the increase of the initial dye concentration and temperature. Adsorption process of acid red 3B on EG has small activation energy. Internal diffusion appears to be the rate-limiting step for the adsorption process.
\end{abstract}

Keywords: Expanded graphite, Adsorption kinetics, Rate-limiting step, Acid red 3B

\section{Introduction}

Most of the industries such as textiles, paper, plastics, leather, food, cosmetic, etc. use dyes or pigments to color their final products. Such extensive uses of color often possess problems in the form of colored wastewaters. Most of the commercially used dyes are resistant to biodegradation, photo degradation and oxidizing agent. Biological methods have not been very successful for dye removal, due to the essential non-biodegradable nature of most of the dyes.

Adsorption is a kind of effective measure, active carbon ${ }^{1-4}$, anion exchange resin ${ }^{5}$, active sludge $e^{6,7}$, peat, steel plant slag and fly $a^{3}{ }^{8}$ have been reported to be employed for the treatment of dyes. Expanded graphite (EG) is a kind of eco-material and it has attracted attentions of scientists and engineers as an absorbent with a high sorption capacity for heavy oil and biomedical molecules ${ }^{9}$. Pores in EG are described using a 4-level model ${ }^{10}$, and the pore size ranges from several $\mathrm{nm}$ to hundreds $\mu \mathrm{m}$, which makes it have the adsorption 
capability for dyes. But it has been reported not so much in this aspect. Wang studied the sorption capacity of EG low-density plate, and a decreasing rate of chemical oxygen demanded of $40 \%$ was obtained ${ }^{11}$. Yang studied the sorption capacity of dyes on $\mathrm{EG}^{12}$, and the decolored rate of medium yellow GG can arrived ${ }^{13}$ to $97 \%$. However, little work has been done to study the adsorption kinetics of dye on EG. In this work, a porous EG was prepared through chemical oxidation and intercalation. An organic dye of acid red 3B with azobenzene structure was used as model adsorbate to study the adsorption kinetics under various experimental conditions.

\section{Experimental}

\section{Preparation and characteristics of EG}

Expandable graphite was prepared with 50 mesh crude graphite (C), and $\mathrm{KMnO}_{4}$ as oxidant, vitriol as intercalation compound. The mass ratio of $\mathrm{C}$ to vitriol and $\mathrm{KMnO}_{4}$ was controlled as 1.0:5.0:0.15. The mass concentration of vitriol was 50\% and the reaction lasted $30 \mathrm{~min}$ at room temperature. After washing to a $\mathrm{pH}$ of 6.0-7.0 and drying below $80^{\circ} \mathrm{C}$, expandable graphite was obtained. Expandable graphite was expanded in KSW heating oven at $900^{\circ} \mathrm{C}$ and EG was obtained. Structural parameters of EG were characterized by expanded volume, specific surface area and total pore volume. The porosity characteristics of EG were listed in Table 1.

Table 1. Structural parameter of $\mathrm{EG}^{\mathrm{a}}$

\begin{tabular}{ccc}
\hline Expanded volume, $\mathrm{mL} / \mathrm{g}$ & Specific surface area, $\mathrm{m}^{2} / \mathrm{g}$ & Total pore volume, $\mathrm{cm}^{3} / \mathrm{g}$ \\
\hline 330 & 1044.99 & 30.1145 \\
\hline
\end{tabular}

a specific surface area and total pore volume are detected with Auto Pore II 9220 Mercury Porosimeter under varying pressures of 0.58 PSIA to 59814.12 PSIA.

\section{Adsorbate}

In this experiment, Acid red3B was selected as model compound for its excellent water solubility, extensive use in coloration and deep chroma. It was supplied by Yuhua trade company, Tientsin, China. The molecular structure and molecular weight is shown in Table 2.

Simulated dye wastewaters were prepared by dissolving dye in distilled deionized water at various concentrations. All color measurements were made with spectrophotometer operating in the visible range on absorbance mode.

Table 2. Chemical structure and molecular weight of Acid red3B

Dcid Red 3B

Adsorption of dye

A series of desired dye concentration and of fixed volume $100.0 \mathrm{~mL}$ were placed in vessels, where they were brought into contact with $\mathrm{EG}$ at $5^{\circ} \mathrm{C}, 25^{\circ} \mathrm{C}$ and $45^{\circ} \mathrm{C}$ respectively. The mass of adsorbent to volume of solution was standardized at $M / V=0.200 \mathrm{~g} / 0.1 \mathrm{l}=2.00 \mathrm{~g} / \mathrm{L}$. The dye solution corresponding to different adsorption time was then analysed using spectrophotometry technique. The amount of Acid red3B captured by EG was calculated as following: 
where:

$$
\mathrm{q}=\mathrm{V}\left(\mathrm{C}_{0}-\mathrm{C}\right) / \mathrm{M}
$$

$\mathrm{q}=$ adsorption amount of acid red $3 \mathrm{~B}$ on $\mathrm{EG}, \mathrm{mg} / \mathrm{g}$

$\mathrm{V}=$ the volume of the solution, $\mathrm{mL}$

$\mathrm{C}_{0}=$ initial concentration of acid red $3 \mathrm{~B}$ in solution; $\mathrm{mg} / \mathrm{L}$

$\mathrm{C}=$ concentration of acid red $3 \mathrm{~B}$ in solution corresponding to a definite adsorption time; $\mathrm{mg} / \mathrm{L}$

$\mathrm{M}=$ mass of EG; $\mathrm{g}$

\section{Results and Discussion}

\section{Equilibrium time}

The amount of dye adsorbed is showed as a function of time in Figure 1. As showed in this figure, adsorption occurs more rapidly at higher temperature: it takes about $2.5 \mathrm{~h}$ to reach the adsorption equilibrium at $45^{\circ} \mathrm{C}$, while it takes about $24.0 \mathrm{~h}$ at $5^{\circ} \mathrm{C}$. Initial dyes concentrations do not have a significant effect on the equilibrium time.

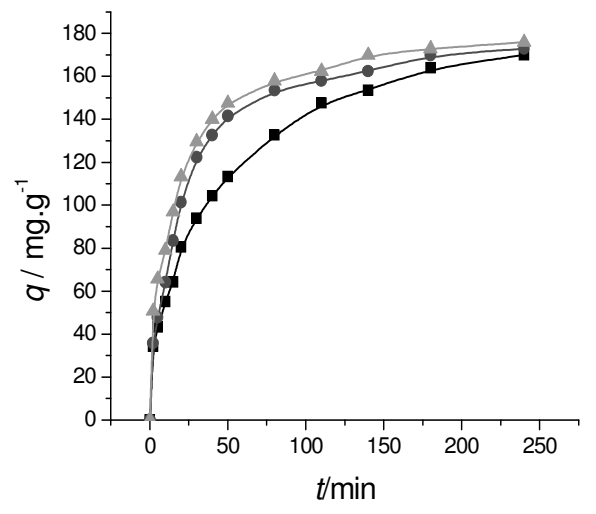

a

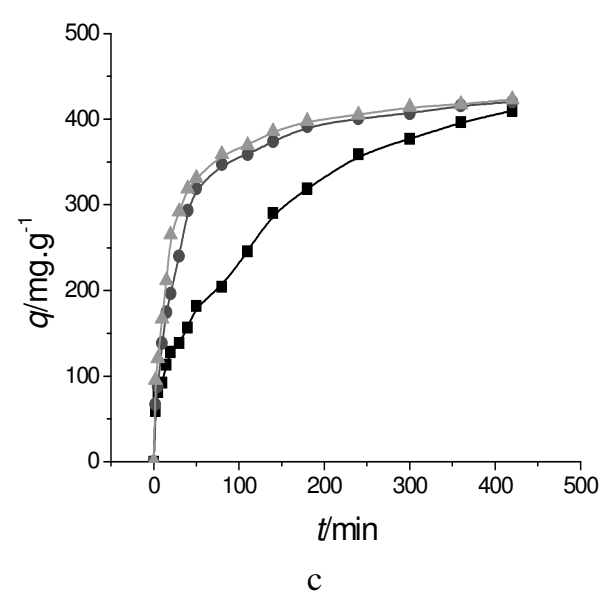

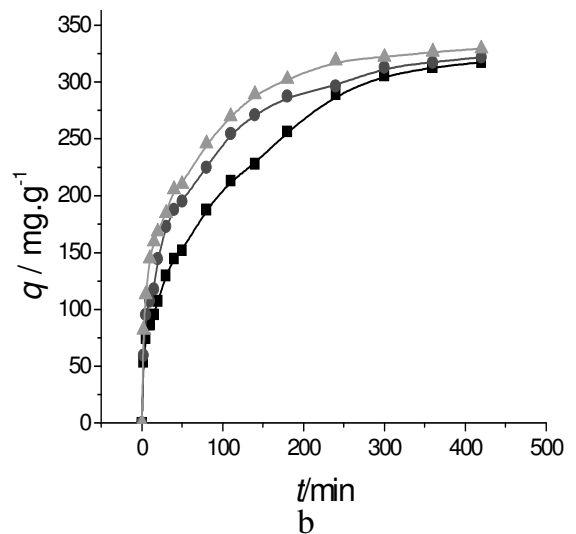

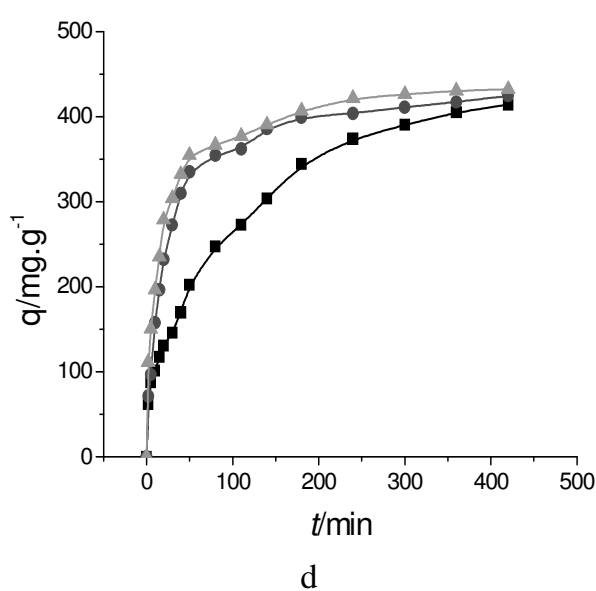

Figure 1. Influence of initial acid red $3 \mathrm{~B}$ concentration and temperature on adsorption kinetics. Initial acid red 3B concentration is (a) $200 \mathrm{mg} / \mathrm{L}$ (b) $400 \mathrm{mg} / \mathrm{L}$ (c) $600 \mathrm{mg} / \mathrm{L}$ (d) $800 \mathrm{mg} / \mathrm{L}(\boldsymbol{\bullet}) 5^{\circ} \mathrm{C}(\bullet) 25^{\circ} \mathrm{C}(\boldsymbol{\Delta}) 45^{\circ} \mathrm{C}$. 


\section{Adsorption kinetic models}

Both pseudo first- and second-order adsorption models were used to describe the adsorption kinetics data ${ }^{14,15}$. In both models, all the steps of adsorption such as external diffusion, internal diffusion, and adsorption are lumped together, and the overall adsorption rate is proportional to either the driving force (as in the pseudo first-order equation) or the square of the driving force (as in the pseudo second-order equation).

First-order model: $\ln \left(q_{e}-q\right)=\ln q_{e}-k t$

Second-order model: $t / q=1 /\left(k q_{e}^{2}\right)+t / q_{e}$

where:

$k=$ adsorption rate constant $\left(\mathrm{min}^{-1}\right.$ for first-order adsorption, $\mathrm{g} \cdot \mathrm{mg}^{-1} \cdot \mathrm{min}^{-1}$ for second-order adsorption)

$t=$ adsorption time ( $\mathrm{min})$

Since $q$ reaches a plateau $\left(q_{\mathrm{e}}\right)$ at equilibrium, $q$ values smaller than the $0.9 q$ e were used for analysis. The plots of $\ln (q \mathrm{e}-q)$ versus $t$ and $t / q$ versus $t$ were used to test the first- and secondorder models, and the fitting results are given in Table 3. According to the correlation coefficients, second-order model gives satisfactory fits, and at the same time, the $q_{\mathrm{e}, \text { cal }}$ corresponding to second-order model agrees more well with the experimental data than the first-order model. Thus, second-order model is more suitable to describe the adsorption kinetics data. Similar results were observed in biosorption of dye Remazol Black B, RB2, PY2 on biomass, BBF on xerogel ${ }^{16-18}$, anionic dye adsorption on cross-linked chitosan beads ${ }^{15,19}$, and polyethylene glycol (PEG) adsorption on zeolite ${ }^{20}$.

Table 3. Comparison of the experiments and the kinetic models of Acid red3B adsorption on EG

\begin{tabular}{|c|c|c|c|c|c|c|c|c|}
\hline \multirow[b]{2}{*}{$\mathrm{C}_{0} \mathrm{mg} / \mathrm{L}$} & \multirow[b]{2}{*}{$\begin{array}{l}\mathrm{T}, \\
{ }^{0} \mathrm{C}\end{array}$} & \multirow[b]{2}{*}{$\begin{array}{l}q_{e, \exp } \\
\mathrm{mg} / \mathrm{g}\end{array}$} & \multicolumn{3}{|c|}{ First-order } & \multicolumn{3}{|c|}{ Second-order } \\
\hline & & & $q_{e, c a l} \mathrm{mg} / \mathrm{g}$ & $\begin{array}{l}\mathrm{k} / 10^{-3} \\
\mathrm{~min}^{-1}\end{array}$ & $\mathrm{r}$ & $\begin{array}{l}\mathrm{q}_{e, c a l} \\
\mathrm{mg} / \mathrm{g}\end{array}$ & $\begin{array}{c}\mathrm{k} \\
\mathrm{g} / \mathrm{g} \cdot \min \end{array}$ & $R$ \\
\hline \multirow{3}{*}{200} & 5 & 170.34 & $159.1 \pm 1.17$ & $21.0 \pm 1.5$ & 0.971 & $183.2 \pm 4.78$ & $5.46 \pm 0.14$ & 0.996 \\
\hline & 25 & 173.34 & $128.5 \pm 1.11$ & $22.0 \pm 1.1$ & 0.985 & $182.8 \pm 1.92$ & $5.47 \pm 0.06$ & 0.999 \\
\hline & 45 & 177.34 & $105.8 \pm 1.09$ & $18.0 \pm 0.92$ & 0.985 & $183.2 \pm 1.71$ & $5.46 \pm 0.05$ & 1.000 \\
\hline \multirow{3}{*}{400} & 5 & 320.2 & $289.3 \pm 1.06$ & $10.1 \pm 0.3$ & 0.992 & $342.5 \pm 11.9$ & $2.92 \pm 0.10$ & 0.992 \\
\hline & 25 & 322.37 & $265.5 \pm 1.14$ & $12.4 \pm 0.7$ & 0.975 & $337.8 \pm 5.64$ & $2.96 \pm 0.05$ & 0.998 \\
\hline & 45 & 332.24 & $215.0 \pm 1.06$ & $10.4 \pm 0.3$ & 0.977 & $342.5 \pm 4.96$ & $2.92 \pm 0.04$ & 0.999 \\
\hline \multirow{3}{*}{600} & 5 & 412.37 & $401.1 \pm 1.11$ & $9.7 \pm 0.2$ & 0.972 & $444.4 \pm 19.9$ & $2.25 \pm 0.10$ & 0.986 \\
\hline & 25 & 423.69 & $264.5 \pm 1.10$ & $10.3 \pm 0.5$ & 0.981 & $438.6 \pm 2.93$ & $2.28 \pm 0.02$ & 1.000 \\
\hline & 45 & 425.65 & $229.1 \pm 1.11$ & $10.5 \pm 0.6$ & 0.976 & $434.8 \pm 2.45$ & $2.3 \pm 0.013$ & 1.000 \\
\hline \multirow{3}{*}{800} & 5 & 415.65 & $403.4 \pm 1.12$ & $11.0 \pm .7$ & 0.974 & $450.5 \pm 15.2$ & $2.22 \pm 0.075$ & 0.992 \\
\hline & 25 & 426.65 & $249.6 \pm 1.13$ & $10.6 \pm 0.7$ & 0.972 & $436.7 \pm 2.46$ & $2.29 \pm 0.01$ & 1.000 \\
\hline & 45 & 436.55 & $219.1 \pm 1.11$ & $10.02 \pm 0.6$ & 0.976 & $444.4 \pm 2.98$ & $2.25 \pm 0.02$ & 1.000 \\
\hline
\end{tabular}

Based on the second-order model, the initial adsorption rate and half-adsorption time are estimated and listed in Table 4 according to the following equations:

$$
\begin{gathered}
\mathrm{u}=\mathrm{kq}_{\mathrm{e}}{ }^{2} \\
\mathrm{t}_{1 / 2}=1 /\left(\mathrm{kq}_{\mathrm{e}}\right)
\end{gathered}
$$

where:

$\mathrm{u}=$ initial adsorption rate $\mathrm{mg} /(\mathrm{g} \cdot \mathrm{min})$

$\mathrm{t}_{1 / 2}=$ half-adsorption time $\mathrm{min}$ 
As showed in Table 4, the initial adsorption rate is found to increase with the increase of the initial acid red 3B concentration and temperature, and the half-adsorption time $t_{1 / 2}$ decrease with the increase of temperature.

Table 4. Kinetic parameters for the second-order adsorption model of acid red 3B adsorption on $\mathrm{EG}^{\text {a }}$

\begin{tabular}{cccccc}
\hline $\begin{array}{c}C_{0} \\
\mathrm{mg} / \mathrm{L}\end{array}$ & $\begin{array}{c}T \\
{ }^{\circ} \mathrm{C}\end{array}$ & $\begin{array}{c}U, \\
\mathrm{mg} / \mathrm{g} \cdot \mathrm{min}\end{array}$ & $\begin{array}{c}t_{1 / 2} \\
\min \end{array}$ & $\begin{array}{c}E_{a} \\
\mathrm{~kJ} / \mathrm{mol}\end{array}$ & $r$ \\
\hline & 5 & $158.42 \pm 4.13$ & $1.08 \pm 0.03$ & & \\
200 & 25 & $164.35 \pm 1.73$ & $1.05 \pm 0.01$ & - & - \\
& 45 & $171.71 \pm 1.60$ & $1.03 \pm 0.01$ & & \\
400 & 5 & $299.38 \pm 10.41$ & $1.07 \pm 0.04$ & & \\
& 25 & $307.60 \pm 5.14$ & $1.05 \pm 0.018$ & - & \\
& 45 & $332.31 \pm 4.67$ & $1.03 \pm 0.01$ & & \\
600 & 5 & $382.61 \pm 17.15$ & $1.08 \pm 0.05$ & & \\
& 25 & $409.30 \pm 2.74$ & $1.04 \pm 0.007$ & $0.407 \pm 0.0021$ & 0.996 \\
& 45 & $416.72 \pm 2.35$ & $1.02 \pm 0.006$ & & \\
\hline & 5 & $383.54 \pm 12.92$ & $1.08 \pm 0.04$ & & \\
& 25 & $416.86 \pm 2.35$ & $1.02 \pm 0.006$ & - & \\
\hline
\end{tabular}

a: "__ "the value of Ea is unavailable

Second-order rate constants listed in Table 3 is used to estimate the activation energy of acid red $3 \mathrm{~B}$ adsorption on EG using Arrhenius equation:

$$
\begin{aligned}
\mathrm{Lnk}=\mathrm{LnA}-\mathrm{Ea} /(\mathrm{RT}) & \\
\text { where: } \mathrm{A} & =\text { pre-exponential factor }\left(\mathrm{g} \cdot \mathrm{mg}^{-1} \cdot \mathrm{min}^{-1}\right) \\
\mathrm{E}_{\mathrm{a}} & =\text { activation energy of adsorption } \quad(\mathrm{kJ} / \mathrm{mol})
\end{aligned}
$$

The slope of plot of lnk versus $1 / T$ is used to evaluate Ea, which was found to be about $0.407 \mathrm{~kJ} \cdot \mathrm{mol}^{-1}$ corresponding to an initial dye concentration of $600 \mathrm{mg} / \mathrm{L}$ (listed in Table 4). Values of $E a$ corresponding to other concentration were ignored for the reason of veracity (with the correlation coefficients less than 0.9000).

\section{Internal diffusion analysis}

The adsorption process on a porous adsorbent generally involves three stages: (i) external diffusion; (ii) internal diffusion (or intra-particle diffusion); (iii) actual adsorption ${ }^{20}$. The adsorption step is usually very fast for the adsorption of organic compounds on porous adsorbents compared to the external or internal diffusion step ${ }^{21}$, and it is known that the adsorption equilibrium is reached within several minutes in the absence of internal diffusion $^{22}$. Thus, the long adsorption equilibrium time in experiments (2.5 24.0h corresponding to adsorption temperature of $5 \sim 45^{\circ} \mathrm{C}$ ) suggests that the internal diffusion may dominate the overall adsorption kinetics.

To provide definite information on the rate-limiting step, an internal diffusion model based on Fick's second law is used to test if the internal diffusion step is the rate-limiting step ${ }^{23}$ :

where:

$$
q=k_{\mathrm{id}} t^{1 / 2}
$$

$k_{i d}=$ internal diffusion constant, $\mathrm{mg} /\left(\mathrm{g} \cdot \mathrm{min}^{1 / 2}\right)$

According to the internal diffusion model, a plot of $q$ versus $t^{1 / 2}$ should give a straight line with a slope $k_{\mathrm{id}}$ and an intercept of zero if the adsorption is limited by the internal 
diffusion process ${ }^{23}$. The relationships between $q$ and $t^{1 / 2}$ at different temperature are shown in Figure 2. Initially in all the cases studied, a linear relationship between $q$ versus $t^{1 / 2}$ with a zero intercept is found, suggesting that the internal diffusion step dominates the adsorption process before the equilibrium is reached.

To see this more clearly, two dimensionless variables are defined, $\xi$ and $\theta$ :

$$
\xi=q / q_{e} ; \quad \theta=t / t_{1 / 2}
$$

Equation (8) can be rewrite as following:

$$
\xi=k^{\prime} \theta^{1 / 2}
$$

where:

$\mathrm{k}^{\prime}=$ dimensionless internal diffusion rate constant

$\xi=$ dimensionless adsorption amount

$\theta=$ dimensionless time

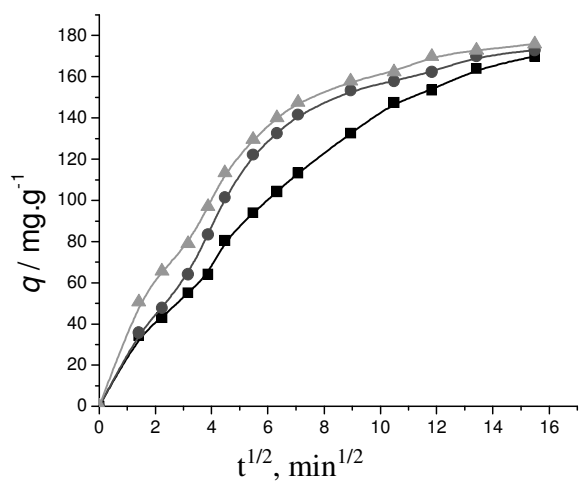

a

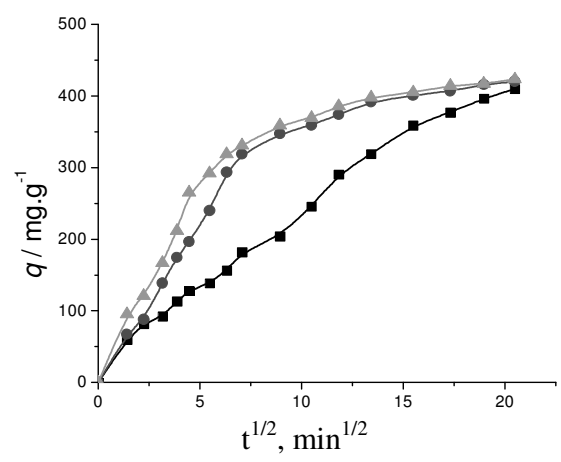

c

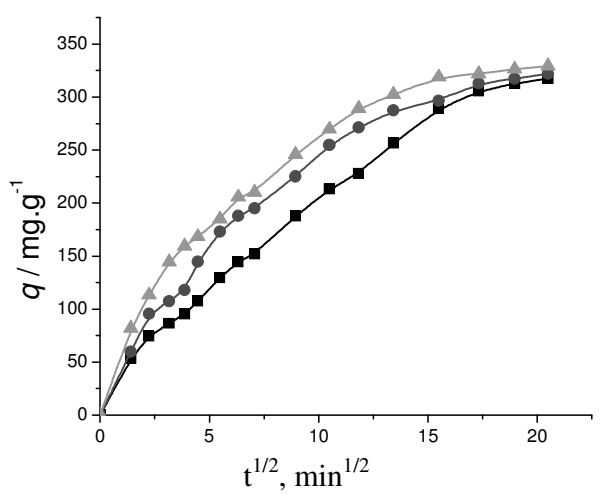

b

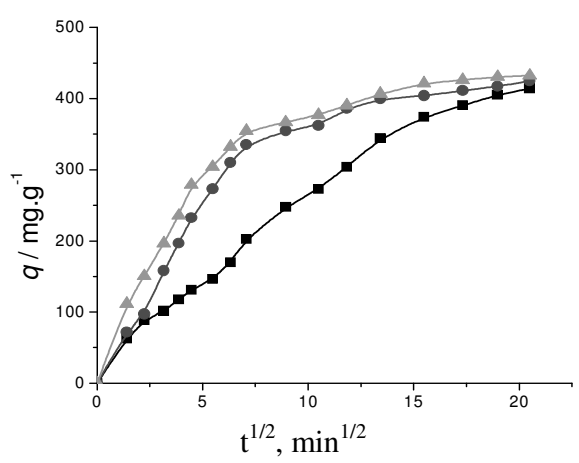

d

Figure 2. Plot of $q$ vs. $t^{1 / 2}$ in internal diffusion model. Initial acid red $3 \mathrm{~B}$ concentration is (a) $200 \mathrm{mg} / \mathrm{L}$, (b) $400 \mathrm{mg} / \mathrm{L}$, (C) $600 \mathrm{mg} / \mathrm{L}$, (d) $400 \mathrm{mg} / \mathrm{L}$; (•) $5^{\circ} \mathrm{C} \mathrm{( \bullet )} 25^{\circ} \mathrm{C}$ ( $\mathbf{\Delta}$ ) $45^{\circ} \mathrm{C}$

Figure 3 shows the plot of $\xi$ versus $\theta^{1 / 2}$, which clearly show that all the data follow the same kinetics. This confirms that the adsorption process can be described by a simple internal diffusion model. For the adsorption of reactive dyes by activated carbon ${ }^{24}$, the adsorption of methylene blue by perlite ${ }^{25}$, and the adsorption of BBF by xerogel ${ }^{17}$, internal diffusion were found to be the rate limiting step. 


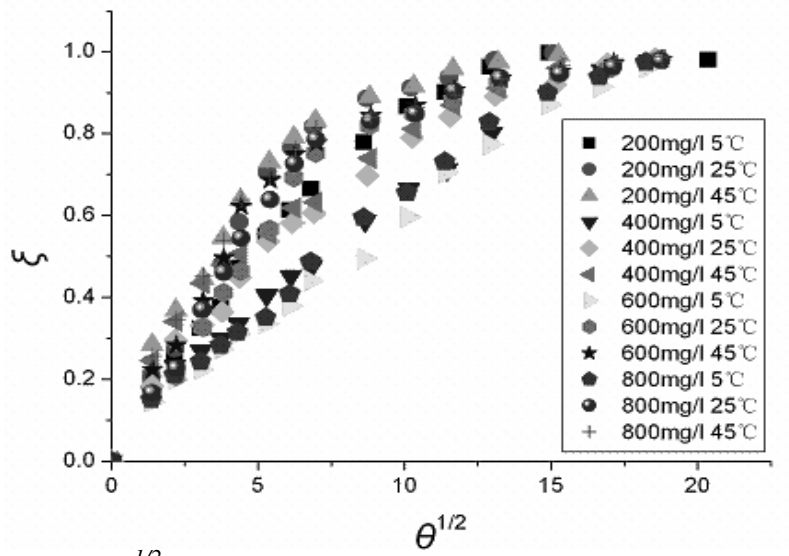

Figure 3. Plot of $\xi$ vs. $\theta^{1 / 2}$ in internal diffusion model. concentration refers to the initial acid red $3 \mathrm{~B}$ concentration.

\section{Conclusions}

The adsorption kinetics characteristics of EG for dye of acid red 3B have been investigated. The results are summarized as follows:

- The adsorption kinetics of EG for acid red 3B can be well described by the pseudo second-order kinetic model. Initial adsorption rate increases with the increase in initial dye concentration and temperature. Equilibrium time and half-adsorption time $t_{1 / 2}$ decreases with the increase of temperature, while the initial dye concentration does not have an obvious effect.

- The equilibrium adsorption amount is found to increase with the increase in initial Acid red3B concentration. The internal diffusion of acid red $3 B$ into the EG is the rate-limiting step of the overall adsorption process.

- Adsorption of acid red 3B on EG has small adsorption activation energy; the result might be caused by the macroporous characteristics of EG.

\section{Acknowledgements}

This study was supported by Doctor Foundation of Hebei province Education Office (China, No.B2004402) and Doctor Foundation of Hebei University. We gratefully acknowledge their support during the study.

\section{Reference}

1. Walker G M and Weatherley L R, Chem Eng J., 2001, 83(3), 201.

2. Namasivayam C and Kavitha D, Dyes and Pigments, 2002, 54(1), 47.

3. Duggan O and Stephen J A, Water Sci Tech., 1997, 35(7), 21.

4. Attia A A, Rashwan W E and Khedr S A, Dyes and Pigments, 2006, 69(3), 128.

5. Silke K, Anja K U and Martin J, Water Res., 2002, 36, 4717.

6. $\quad$ Chu H C and Chen K M, Process Biochem., 2002, 37(6), 595.

7. Chu H C and Chen K M, Process Biochem., 2002, 37(10), 1129.

8. Jain A K, Gupta V K and Bhatnagar A S, J Hazard Mater., B, 2003. 101, 31.

9. Kang F Y, Zheng Y P, Zhao H, Wang H N, Wang L N, Shen W C and Inagaki M, New Carbon Mater, 2003, 18(3), 161. 
10. Zhao H, Zhou W, Cao N Z, Shen W C and Zheng Y P, Mater Sci Eng., 2002, 20(2), 153.

11. Wang L N, Chen X, Zheng Y P, Kang F Y, Chen J F and Shen W C, Guide J Chinese Nonmeteal Mine Ind., 2004, 5, 59.

12. Yang L N, MS Thesis, "Study on the sorption and decoloration of expanded graphite for dyes". Hebei Normal University, Shijiazhuang, China, 2004.

13. Li J H, Yang L N and Wu G, Environ Protect Chem Ind., 2004, 24(S1), 374.

14. Chiou M S and Li H Y, Chemosphere, 2003, 50(8), 1095.

15. Chiou M S and Li H Y, J Hazard Mater., 2002, 93(3), 233.

16. Aksu Z and Tezer S, Process Biochem., 2000, 36(5), 431.

17. Wu Z J, Joo H and Lee K, Chem Eng J., 2005, 112 (1-3),227.

18. Aksu Z, Biochem Eng J., 2001, 7(1), 79.

19. Chiou M S, Ho P Y and Li H Y, Dyes and Pigments, 2004, 60(1), 69.

20. Chang C Y, Tsai W T, Ing C H and Chang C F, J Colloid Interface Sci., 2003, 260(2), 273.

21. Sarkar M, Acharya P K and Bhattacharya B, J Colloid Interface Sci., 2003, 266(1), 28.

22. Mak S Y and Chen D H, Dyes and Pigments. 2004, 61(1), 93.

23. Bhattacharyya K G and Sharma A, J Environ Manage., 2004, 71(3): 217.

24. Yang X Y and Al-Duri B, J Colloid Interface Sci., 2005, 287, 25.

25. Dogan M, Alkan M, Turkyilmaz A and Ozdemir Y, J Hazard Mater., 2004, 109 (1-3), 141. 


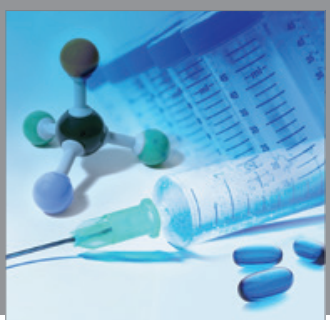

International Journal of

Medicinal Chemistry

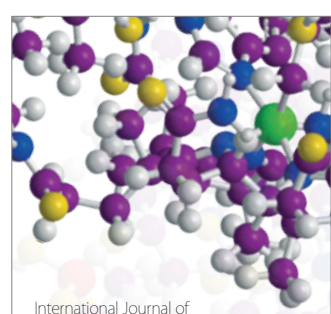

Carbohydrate Chemistry

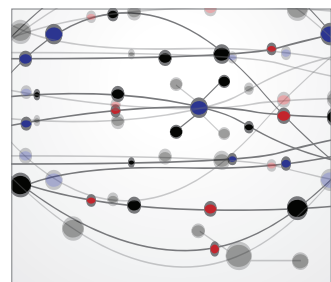

The Scientific World Journal
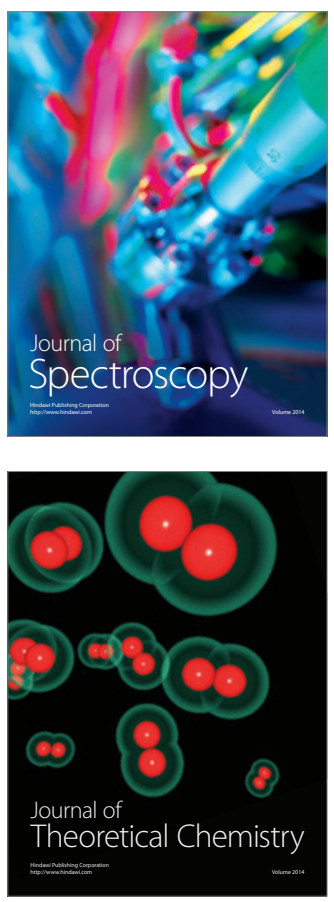
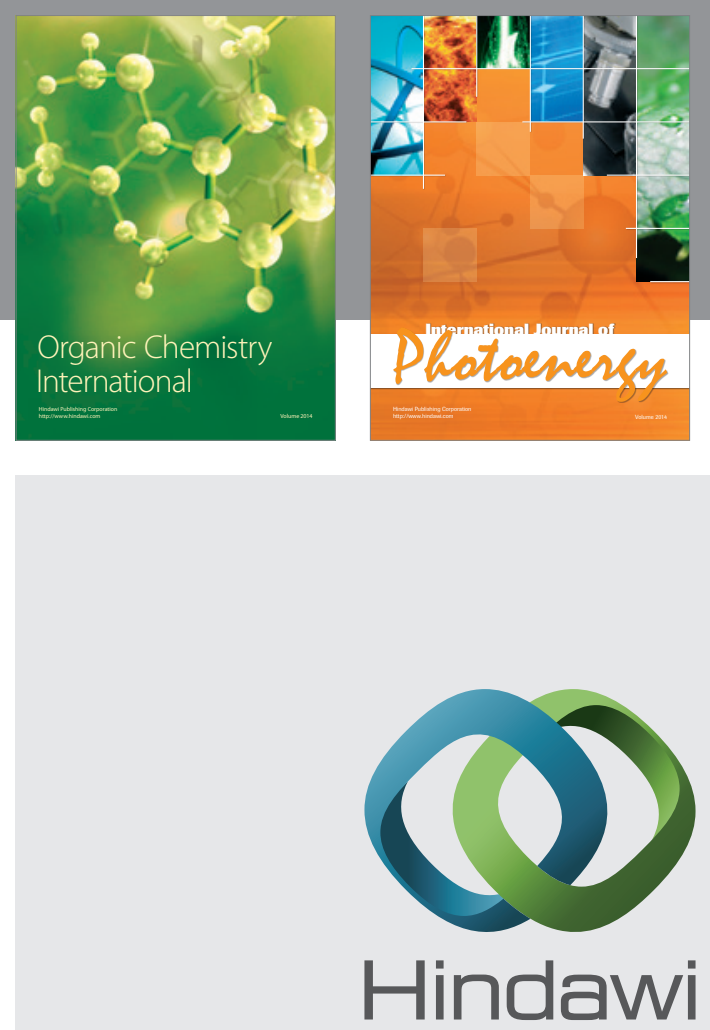

Submit your manuscripts at

http://www.hindawi.com
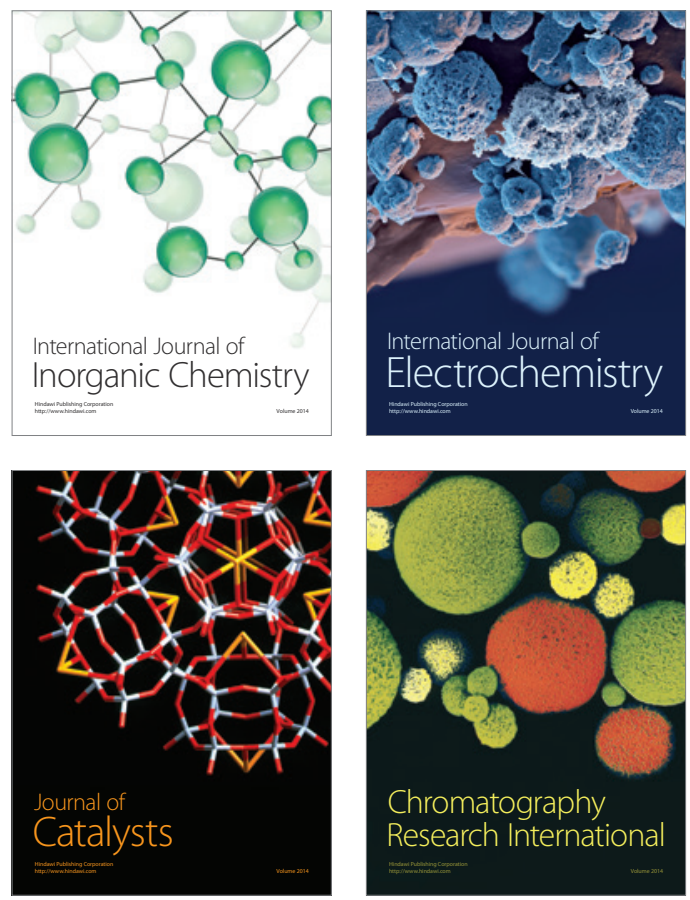
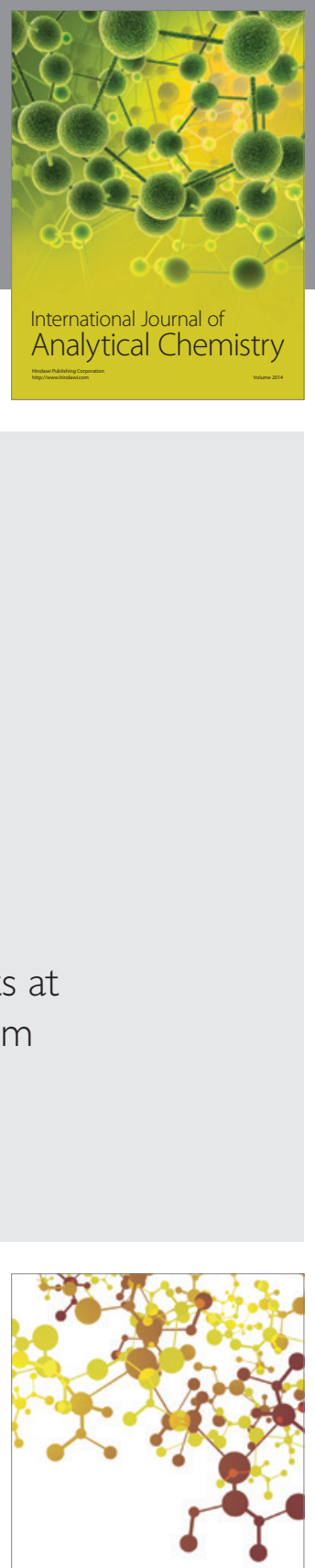

Journal of

Applied Chemistry
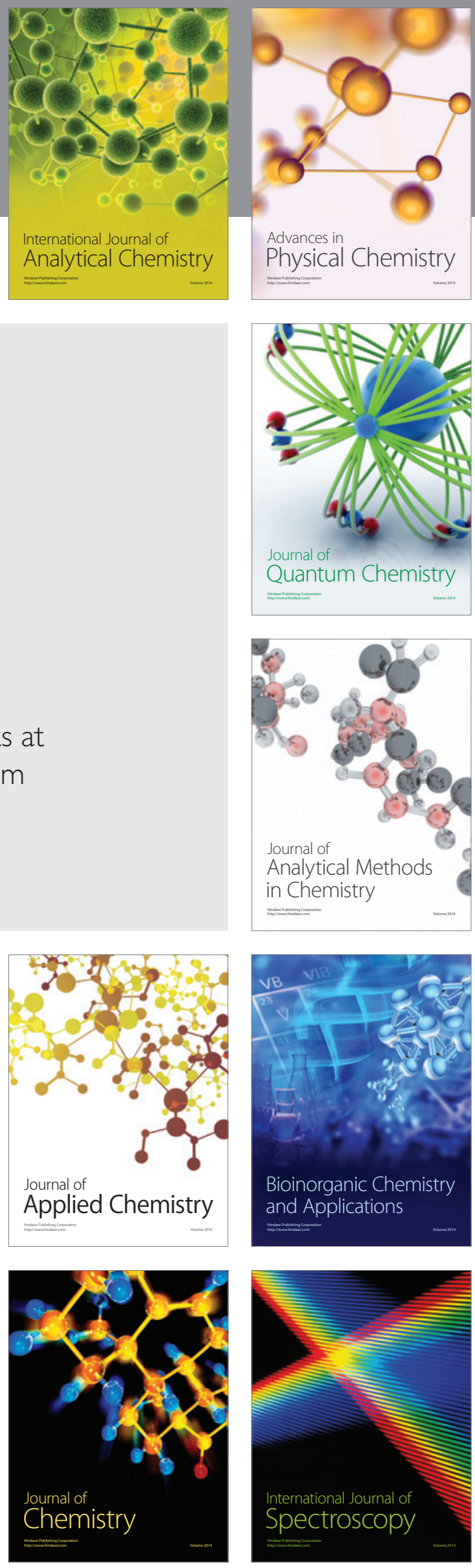